\title{
Use of orthodontic extrusion as aid for restoring extensively destroyed teeth: a case series
}

Giuseppe Troiano $^{1}$, Bruno Parente ${ }^{2}$, Luigi Laino ${ }^{1}$, Mario Dioguardi $^{1}$, Gabriele Cervino ${ }^{2}$, Marco Cicciù ${ }^{2}$, Domenico Ciavarella ${ }^{1}$ and Lorenzo Lo Muzio ${ }^{1}$

${ }^{1}$ Department of Clinical and Experimental Medicine, Foggia University, Foggia, Italy

${ }^{2}$ Department of Human Pathology, University of Messina, Messina, Italy

\begin{abstract}
Forced orthodontic extrusion may represent a valid option for clinicians in different clinical situations. Extrusive movements lead to an improvement in the vertical amount of both hard and soft tissues. Major advantages of this procedure are related to the quality of the regenerated tissues, since they determine the vertical apposition of new endogenous bone. In this paper, we report a case series in which forced orthodontic extrusion in combination with other, surgical- or nonsurgicaltechniques, led to recovery of "hopeless" teeth and avoided implant-supported restorations. In some cases a surgical fiberotomy was performed in order to improve the amount of healthy tissues available for the subsequent restoration. A long term follow up revealed that a multidisciplinary approach including: endodontic therapy, surgical crown lengthening or/and orthodontic extrusion followed by rehabilitation with fixed partial prosthesis (FPP) could lead to long survival rate even for "hopeless" teeth. These procedures have the aim to expose a sufficient amount of circumferential healthy tooth tissues that is fundamental to obtain a ferrule effect for the subsequent prosthetic restoration. Forced orthodontic extrusion represents an important technique in the hands of clinicians for the resolution of difficult situations. Although it is a safety and predictive technique, collaboration by the patient is necessary, in order to achieve desired results at the end of the extrusion period.
\end{abstract}

\section{Introduction}

The recovery of extensive destroyed teeth represents one of the most important challenges for dentists. In the last years, the frequent use of dental implants led a reduction in the execution of recovery procedures of widely destroyed teeth [1,2]. However, whenever possible, the conservative procedures should be preferred to the implant therapies because of the absence of periodontal ligament in implants compared to teeth restorations. Furthermore, the implant positioning may be subsequently performed in the event of failure of conservative therapies [3]. The periodontal ligament works as a shock absorber, absorbs the occlusal loads and determines a better discharge of the forces at the root interface level. Prosthetic and periodontal factors should be taken into account in order to obtain long-term success in this type of treatments. For a correct restore of the "biologic width", different kinds of therapies may be performed such as: surgical crown lengthening combined, or not, with orthodontic extrusion [4]. The final aim of these procedures is to expose a sufficient amount of circumferential healthy tooth tissues. In fact, an amount of 1.5-2.0 $\mathrm{mm}$ in height and $1.0 \mathrm{~mm}$ in width is required in order to obtain the "ferrule effect" which strongly decreases the rate of vertical fractures [5]. To improve the longevity of restorations, another factor to take into account is the crown-root ratio. In fact, failure to comply with this parameter is one of the major source of failure [6]. Surgical crown lengthening procedure provides for an apical flap repositioning after osteotomy procedures, which permit the reestablishment of a new "biologic width". However, this approach leads to a decrease of the amount of root portion in the bone (worsening of the crown/root ratio) and a gingival repositioning. In the anterior sector, this could lead to an incorrect gingival alignment and determines esthetic problems [7]. Orthodontic tooth extrusion is a less invasive approach, in which there is no interference with the periodontium of neighboring teeth; nevertheless this technique requires a better patient compliance [8]. The coronal migration of periodontal tissues during and after dental extrusion seems to be induced by the tension provoked by gingival fibers; in fact, performing a supracrestal fiberotomy during the period of extrusion may prevent the coronal migration of bone and gingival tissues. In this way, at the end of extrusion and retention periods a greater amount of healthy tooth structure could have been moved coronally and be available for the subsequent prosthetic rehabilitation [9]. This procedure is indicated for the recovery of teeth with partial subgingival fracture, since it exposes the healthy tissues in the oral cavity allowing a subsequent rehabilitation [10]. Extrusive movements also determine enhanced amount of soft tissues by increasing the width of attached gingiva [11]. It has been demonstrated that during the extrusion movements the gingival margins migrates coronally but the level of the mucogingival junction remains at the same level [12]. As above mentioned, this technique leads to increment of both soft and hard tissues, the gain is significant because it happens on the vertical plane and, as it is known, such success is difficult to achieve with the current surgical regenerative procedures [13]. Another advantage is related to the quality of the regenerated tissues, because the extrusive

Correspondence to: Dr. Giuseppe Troiano, Via Rovelli, 50, 71122 Foggia, Italy, Tel: 0039-0881-588090; Fax 00390881 588081; E-mail: giuseppe.troiano@unifg.it

Received: May 29, 2016; Accepted: June 16, 2016; Published: June 20, 2016 
procedures lead to apposition of new "endogenous" bone that is the best possible result to be obtained [14]. In addition, it seems that orthodontic extrusion could be an option in periodontal therapy aiming to reduce angular periodontal bony defects $[15,16]$. In this paper, we report a case series of teeth restored with a multidisciplinary approach, involving the use of orthodontic extrusion in different clinical situations.

\section{Patients and methods}

\section{Case 1}

A 36-years-old female patient referred to our observation, complained a fracture of the lingual surface of the element 4.5. At the clinical examination, the tooth presented a destructive decay with a fracture of the lingual wall up to cervical line. The radiographic examination revealed the presence of a radiolucent periapical lesion. To start, a composite provisional restoration was built without the insert of a fiber post. Subsequently, the patient mounted a fixed orthodontic appliance in order to have an extrusion of the root and expose the cervical margin of the tooth. The orthodontic therapy was carried out for two months in combination with a coronal odontoplasty to allow the extrusion of the tooth in the arch. After removing the orthodontic, a surgical crown lengthening was performed in order to improve the amount of healthy tissues exposed to the oral cavity, increase the retention of the later restoration and maintain the biological width. After the healing period, a custom post was built and cemented to the root canal. The final restoration was built after a second provisional restoration that was used to improve soft tissues conditioning. A polyether base impression (Impregum; $3 \mathrm{M} \mathrm{ESPE}^{\star}$ ) was carried out after the placement of two retraction cords. Finally, a ceramic-metal crown was cemented using GC Luting and Lining cement (GC Corporation). After a ten years follow-up, the restoration and soft tissues appear to still be in good health conditions (Figure 1).

\section{Case 2}

A 44-years-old male reported to our department for a general dental examination, the patient wanted restore the element 1.5 who fractured itself 3 months before. At the clinical examination, this tooth appeared destroyed and decayed, with the dental margin positioned at subgingival level. Radiographic examination with an intraoral periapical radiograph revealed the presence of a radiolucent periapical lesion. The patient refused the implant therapy, so we decided to

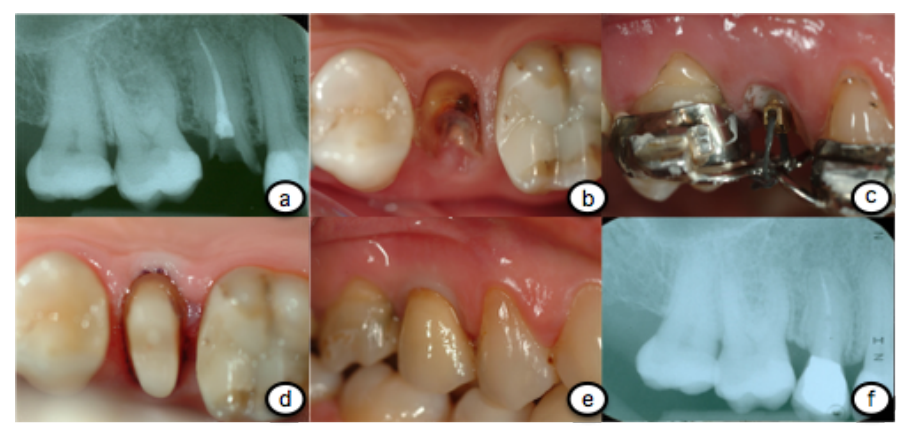

Figure 1. a: Endoral $X$ ray underlines the deep caries disease at the inferior premolar destroying the whole tooth crown. b: Occlusal view of the destroyed inferior second premolar. Gingiva is growing on the lesion and this is because the patient underestimated the progress of the disease. c: Endoral X ray after the endodontic treatment performed on the previous destroyed tooth. d: Conservative treatment and then orthodontic extrusion of the residual reconstructed tooth has been performed. e: After the two months orthodontic treatment the extrusion of the premolar has been obtained. e: A prosthetic abutment has been prepared and the residual gap has been covered by endodontic indirect post. f: Occlusal view of the final ceramic crown positioned. perform a multidisciplinary therapy including: endodontic treatment, orthodontic extrusion and prosthetic rehabilitation. In addition, the patient asked us the utmost respect for its aesthetics during orthodontic procedures. For this reason, after the endodontic therapy, we built a custom device with two orthodontic bands, which served as anchorage for the extrusion forces. To transmit forces to the root, a prefabricated post was leaning against the canal walls and was put on traction with an elastic thread. The orthodontic extrusion was carried out for a period of 6 weeks, and a supracrestal fiberotomy with concurrent root planning was performed once a week during the extrusion period. After another three months of stabilization, a restoration with a fiber post was carried out and a provisional crown was cemented. Subsequently, a polyvinyl siloxane rubber base impression was taken (Exa'lence', GC Corporation) on the final crown preparation for the crown construction. Radiographic evaluation at 8 years follow-up revealed a healthy condition for both endodontic and periodontal tissues (Figure 2).

\section{Case 3}

A 54-years-old male was referred to our institute; he complained the accumulation of food and debris under a fixed partial prosthesis on teeth 4.4 and 4.5. Radiographic evaluation revealed a wide destruction of 4.5 who, in the past, was restored with a screwed pin. After the fixed partial dentures removal, it was possible to see the little amount of healthy hard tissues remaining, which were located at a deep subgingival level. The patient strongly refused the replacement of such tooth with osseointegrated implants that was proposed as best option; therefore also in this case we opted for a multidisciplinary approach. At radiographic examination the tooth did not present periapical lesions, so we decided to first perform the orthodontic extrusion and treat subsequently the root canal. The old FPP was modified in order to work as anchorage for the extrusion. The extrusion period lasted for 8 weeks and a surgical fiberotomy with root planning was performed once a week. Afterwards, 3 months of stabilization were needed for the healing processes. Surgical crown lengthening procedure was performed to improve the amount of tissues exposed and restore the biologic width. Because the amount of intrabony root was small and root-crown ratio was unfavorable, we decided to splint both the crowns of 4.4 and 4.5. Following a healing period of one month, the canal of the tooth was retracted and a fiber post was bonded to restore the tooth abutment. A precision impression with Polyether was made and it served for the construction of a newly fixed partial denture on the teeth 4.4 and 4.5. Despite the bad root/crown ratio, to a follow-up of 9 years the fixed rehabilitation does not present problems (Figure 3).

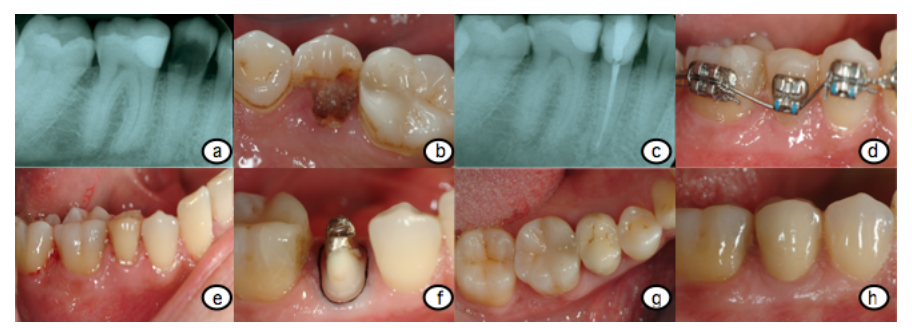

Figure 2. a: A second premolar with endodontic treatment performed and with total crown destroyed is evidenced in the endoral $\mathrm{x}$ ray investigation; $\mathbf{b}$ : The clinical view of the second premolar. Just the root is evidenced in this occlusal clinical view; c: A screwed post is positioned inside the root in order to create a connection with the two adjacent teeth for orthodontic extrusion; d: After the extrusion the abutment is rebuilt in order to receive prosthetic crown restoration; e: Ceramic crown restoration has been placed on the prepared abutment; f: The $\mathrm{x}$ ray post treatment show the perfect fit of the prosthetic crown and the no bone resorption around the treated tooth 


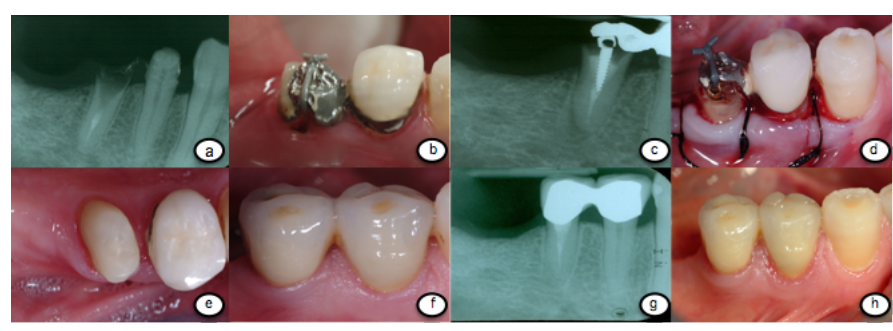

Figure 3. a: Endoral X-ray underlines the deep caries disease at the inferior premolar destroying all the tooth parts. A residual root with endodontic treatment performed is recorded. b: The old fixed partial denture was modified in order to work as anchorage for the extrusion. c:Endoral X ray after 8 weeks orthodontic extrusion. d: Surgical crown lengthening was performed to improve the amount of tissues exposed and restore the biologic width. e:Occlusal view of the abutment realized after the performed extrusion of the root. f: Final restoration of the two element with ceramic prosthetic crown. g: Endoral $\mathrm{X}$ ray underlining perfect fit of the two prosthetic crowns and no sign of inflammation at the teeth apex or roots. $\mathbf{h}$ : Final restoration at a follow-up of 8 years.

\section{Discussion}

Recently, the replacement of missing and destroyed teeth with implant fixtures represents one of the most common procedures during the clinical practice $[17,18]$. Although, implants present a high survival rate, some patients refuse their use [19]. When possible clinicians should prefer the recovery of strongly destroyed teeth above all in young patients, so as to perform implants in a more mature age [20,21]. The recovery of destroyed teeth requires a multidisciplinary approach including: endodontic therapy, crown lengthening or/and orthodontic extrusion and prosthetic rehabilitation [22]. The orthodontic extrusion allows the displacement of both hard and soft tissues, through its action on supracrestal fibers [23]. If the extrusion is accompanied to a surgical fiberotomy once a week, it will determine the displacement of dental tissues alone [22]. Gingival recession represent the most common side effect of this procedure, and it is evident especially in patients with a thin thickness of buccal bone [24]. Kozlovsky et al. [25] suggested the adding of root planning to supracrestal fiberotomy every two weeks in order to decrease the attachment of fibers on the root. Traditionally, forced extrusions have been performed alone or in combination with surgical procedures for clinical crown lengthening. Carvalho et al. [9] compared the orthodontic extrusion alone (Group B) with the same technique combined with fiberotomy and root planning (Group A). They found that in Group A there was a greater amount of dental structure exposed and, the level of gingival margin and bone tissues remain stable. The time required for extrusion varies depending on the amount of tissue to be extruded. Simon et al. [26], suggested 1 to 3 weeks for the activation and 8 to 12 weeks for the stabilization of teeth in the final position. The amount of vertical bone deposition was first studied by Van Venrooy and Yukna [27], they reported a mean of $2.00 \mathrm{~mm}$ of crestal bone deposition after three weeks of orthodontic extrusion. There is no uniformity in the literature about the strategy used for the orthodontic extrusion. To transmit a force for extrusion, it is necessary to provide a stable anchorage that acts as a support for the discharge of the forces on the element to be extruded. Modified provisional restoration [16], fixed orthodontic appliances [28] or mini-implant screw [29] could be used for the anchorage vary depending on the clinical situation. In this case series we also used a provisional screwed post for better discharge of the forces at the level of the root. In our opinion, although this is a more invasive technique, for severely destroyed teeth it could be safely used and determines a better anchorage than bonded fiber posts. The forced orthodontic extrusion has also been recently used for the development of bone for pre-implant site enhancement [30]. In the anterior region this can be essential to obtain an aesthetic implant rehabilitation with alignment of the gingival parables [31]. In this paper, we report three cases of multidisciplinary approach, containing orthodontic extrusion, for the recovery of strongly destroyed teeth in the posterior region. In the clinical practice, this is the most frequent and comfortable situation to perform orthodontic extrusion. In fact, the majority of patients refuse to perform these procedures in the anterior region for aesthetic reasons, while, in the posterior region, this technique may be performed without aesthetic sequelae. For posterior teeth, the exposure of the margin to 360 degrees is one of the most important prerequisites for a long-lasting prosthetic rehabilitation [32]. The three cases reported in this paper have a mean follow up of 10 years and the patient satisfaction is very high. In our experience, one of the most important problems following the orthodontic extrusion is the amount of root remaining in the bone. In fact, this could lead to a disadvantageous root/crown ratio and increase the risk of fracture. In these situations the risk of fracture could be decreased soldering the crown of the tooth with the crown of the neighbor element as reported in the case 2 .

\section{References}

1. Moghaddam AS, Radafshar G, Taramsari M, Darabi F (2014) Long-term survival rate of teeth receiving multidisciplinary endodontic, periodontal and prosthodontic treatments. J Oral Rehabil 41: 236-242. [Crossref]

2. Giannobile WV, Lang NP (2016) Are Dental Implants a Panacea or Should We Better Strive to Save Teeth? J Dent Res 95: 5-6. [Crossref]

3. Setzer FC, Kim S (2014) Comparison of long-term survival of implants and endodontically treated teeth. J Dent Res 93: 19-26. [Crossref]

4. Zenobio EG, Moreira RC, Soares RV, Feres M, Chambrone L, et al. (2015) A mixedmodel study assessing orthodontic tooth extrusion for the reestablishment of biologic width. A systematic review and exploratory randomized trial. Int J Periodontics Restorative Dent 35: 19-27. [Crossref]

5. Mamoun JS (2014) On the ferrule effect and the biomechanical stability of teeth restored with cores, posts, and crowns. Eur J Dent 8: 281-286. [Crossref]

6. Tada S, Allen PF, Ikebe K, Zheng H, Shintani A, et al. (2015) The Impact of the CrownRoot Ratio on Survival of Abutment Teeth for Dentures. J Dent Res 94 (9 Suppl): 220S-225S. [Crossref]

7. Deas DE, Mackey SA, Sagun RS Jr, Hancock RH, Gruwell SF, et al. (2014) Crown lengthening in the maxillary anterior region: a 6-month prospective clinical study. Int $J$ Periodontics Restorative Dent 34: 365-373. [Crossref]

8. Brindis MA, Block MS (2009) Orthodontic tooth extrusion to enhance soft tissue implant esthetics. J Oral Maxillofac Surg 67 (11 Suppl): 49-59. [Crossref]

9. Carvalho CV, Bauer FP, Romito GA, Pannuti CM, De Micheli G (2006) Orthodontic extrusion with or without circumferential supracrestal fiberotomy and root planing. Int J Periodontics Restorative Dent 26: 87-93. [Crossref]

10. Ré JP, Orthlieb JD (2016) Rapid orthodontic extrusion of a subgingivally fractured incisor. $J$ Prosthet Dent. [Crossref]

11. Batenhorst KF, Bowers GM, Williams JE Jr (1974) Tissue changes resulting from facial tipping and extrusion of incisors in monkeys. J Periodontol 45: 660-668. [Crossref]

12. Ainamo J, Talari A (1976) The increase with age of the width of attached gingiva. $J$ Periodontal Res 11: 182-188. [Crossref]

13. Milinkovic I, Cordaro L (2014) Are there specific indications for the different alveolar bone augmentation procedures for implant placement? A systematic review. Int J Oral Maxillofac Surg 43: 606-625. [Crossref]

14. Berglundh T, Marinello CP, Lindhe J, Thilander B, Liljenberg B (1991) Periodontal tissue reactions to orthodontic extrusion. An experimental study in the dog. $J$ Clin Periodontol 18: 330-336. [Crossref]

15. Ingber JS (1974) Forced eruption. I. A method of treating isolated one and two wall infrabony osseous defects-rationale and case report. J Periodontol 45: 199-206. [Crossref]

16. Fakhry A (2007) Enhancing restorative, periodontal, and esthetic outcomes through orthodontic extrusion. Eur J Esthet Dent 2: 312-320. [Crossref]

17. Albrektsson T, Donos N; Working Group (2012) Implant survival and complications 
The Third EAO consensus conference 2012. Clin Oral Implants Res 23 Suppl 6: 63-65. [Crossref]

18. Ayaz M, Kharbanda OP. Successful treatment of Class II malocclusion with bidental protrusion using standard edgewise prescription. Contemp Clin Dent 7: 75-78. [Crossref]

19. Bellini M, Maltoni O, Gatto MR, Pelliccioni G, Checchi V, et al. (2008) Dental phobia in dentistry patients. Minerva Stomatol 57: 485-495. [Crossref]

20. Nasseh AA, Vafaie N, Dayan S (2014) Tooth preservation vs. implant therapy: what's best for the patient? Compend Contin Educ Dent 35: 14-16. [Crossref]

21. Rosa M, Lucchi P, Ferrari S, Zachrisson BU, Caprioglio A (2016) Congenitally missing maxillary lateral incisors: Long-term periodontal and functional evaluation after orthodontic space closure with first premolar intrusion and canine extrusion. $\mathrm{Am} J$ Orthod Dentofacial Orthop 149: 339-348. [Crossref]

22. Pontoriero R, Celenza F Jr, Ricci G, Carnevale G (1987) Rapid extrusion with fiber resection: a combined orthodontic-periodontic treatment modality. Int $J$ Periodontics Restorative Dent 7: 30-43. [Crossref]

23. Kajiyama K, Murakami T, Yokota S (1993) Gingival reactions after experimentally induced extrusion of the upper incisors in monkeys. Am J Orthod Dentofacial Orthop 104: 36-47. [Crossref]

24. Alsahhaf A, Att W (2016) Orthodontic extrusion for pre-implant site enhancement: Principles and clinical guidelines. J Prosthodont Res. [Crossref]

25. Kozlovsky A, Tal H, Lieberman M (1988) Forced eruption combined with gingival fiberotomy. A technique for clinical crown lengthening. J Clin Periodontol 15: 534538. [Crossref]

26. Simon JH, Kelly WH, Gordon DG, Ericksen GW (1978) Extrusion of endodontically treated teeth. J Am Dent Assoc 97: 17-23. [Crossref]

27. van Venrooy JR, Yukna RA (1985) Orthodontic extrusion of single-rooted teeth affected with advanced periodontal disease. Am J Orthod 87: 67-74. [Crossref]

28. Sonmez H, Tunc ES, Dalci ON, Saroglu I (2008) Orthodontic extrusion of a traumatically intruded permanent incisor: a case report with a 5-year follow up. Dent Traumatol 24: 691-694. [Crossref]

29. Greco M, Derton N (2012) Orthodontic extrusion for a preprosthetic approach a bracketless mini-implant-based mechanics. Orthodontics (Chic) 13: 210-215. [Crossref]

30. Salama H, Salama M (1993) The role of orthodontic extrusive remodeling in the enhancement of soft and hard tissue profiles prior to implant placement: a systematic approach to the management of extraction site defects. Int $J$ Periodontics Restorative Dent 13: 312-333. [Crossref]

31. Maiorana C, Speroni S, Herford AS, Cicciu M (2012) Slow Orthodontic Teeth Extrusion to Enhance Hard and Soft Periodontal Tissue Quality before Implant Positioning in Aesthetic Area. Open Dent J 6: 137-142. [Crossref]

32. Juloski J, Radovic I, Goracci C, Vulicevic ZR, Ferrari M (2012) Ferrule effect: a literature review. J Endod 38: 11-19. [Crossref]

Copyright: $\odot 2016$ Troiano G. This is an open-access article distributed under the terms of the Creative Commons Attribution License, which permits unrestricted use, distribution, and reproduction in any medium, provided the original author and source are credited. 